Farum

Sociológico

\section{Forum Sociológico}

Série II

$35 \mid 2019$

Arte urbana: Contextos, tendências e desafios

\title{
Regeneração urbana através da cultura e das artes : o caso do Barreiro
}

Urban regeneration through culture and arts: the case of Barreiro

André Carmo, Filipe Matos e Sónia Pereira

\section{(2) OpenEdition}

Journals

Edição electrónica

URL: https://journals.openedition.org/sociologico/8670

DOI: $10.4000 /$ sociologico.8670

ISSN: 2182-7427

Editora

CICS.NOVA - Centro Interdisciplinar de Ciências Sociais da Universidade Nova de Lisboa

\section{Edição impressa}

Paginação: 61-70

ISSN: 0872-8380

\section{Refêrencia eletrónica}

André Carmo, Filipe Matos e Sónia Pereira, «Regeneração urbana através da cultura e das artes : 0 caso do Barreiro», Forum Sociológico [Online], 35 | 2019, posto online no dia 11 dezembro 2019, consultado o 29 março 2022. URL: http://journals.openedition.org/sociologico/8670 ; DOI: https:// doi.org/10.4000/sociologico.8670 


\title{
REGENERAÇÃO URBANA ATRAVÉS DA CULTURA E DAS ARTES: O CASO DO BARREIRO ${ }^{1}$
}

\section{URBAN REGENERATION THROUGH CULTURE AND ARTS: THE CASE OF BARREIRO}

\author{
André Carmo \\ Departamento de Geociências, Escola de Ciências e Tecnologia da Universidade de Évora / Centro de Estudos \\ Geográficos, Instituto de Geografia e Ordenamento do Território da Universidade de Lisboa, Departamento de Geociências \\ (CEG - IGOT ULisboa)

\section{Filipe Matos} \\ Centro de Estudos Geográficos, Instituto de Geografia e Ordenamento do Território da Universidade de Lisboa \\ (CEG - IGOT ULisboa)

\section{Sónia Pereira} \\ Centro de Estudos Geográficos, Instituto de Geografia e Ordenamento do Território da Universidade de Lisboa \\ (CEG - IGOT ULisboa)
}

\begin{abstract}
Resumo
Adoptando uma perspectiva eminentemente hermenêutico-interpretativa, centrada na análise do discurso e das representações, este artigo pretende contribuir para a compreensão do actual processo de regeneração urbana do Barreiro. Se, por um lado, coloca a tónica no papel que nele desempenham a cultura e as artes, por outro, procura também descrever e interpretar as relações que se estabelecem com a memória e a identidade, enquanto traços constitutivos e definidores de um território profundamente marcado pelo seu passado. A partir da leitura crítica de um conjunto de 15 entrevistas realizadas a actores-chave que possuem um conhecimento aprofundado da realidade local, presente e passada, procura-se reconstituir uma narrativa inteligível que nos ajude a interrogar, a problematizar e a dar sentido ao processo investigado, designadamente ao nível das inter-relações e dinâmicas socioterritoriais existentes e dos discursos subjacentes.
\end{abstract}

Palavras-chave: Barreiro, regeneração urbana, cultura, artes

\section{Abstract}

Adopting an eminently hermeneutic-interpretative perspective, centered on the analysis of discourse and representations, this article aims to contribute to the understanding of the current process of urban regeneration of Barreiro. If, on the one hand, it emphasizes the role that culture and the arts play in it, on the other, it also seeks to describe and interpret the relations that are established with memory and identity, as constitutive and defining features of a territory deeply marked by its past. From the critical reading of a set of 15 interviews conducted with key actors who have a thorough knowledge of the local reality, present and past, we seek to reconstruct an intelligible narrative that helps us interrogate, problematize and make sense of the process, namely in terms of interrelationships and existing socio-territorial dynamics and underlying discourses.

Keywords: Barreiro, urban regeneration, culture, arts 
Introdução

Sem deixar de ser polémico e controverso (Campbell et al., 2017; Vickery, 2007), o importante papel que a cultura e as artes podem desempenhar na transformação territorial é hoje consensual. Ao longo das últimas décadas, um conjunto vasto de experiências e projectos, intervenções e iniciativas tem sido implementado, promovido pelos mais diferentes actores, demonstrando que a cultura e as artes podem ser instrumentos importantes para a melhoria da qualidade de vida e a promoção do bem-estar das populações, para o desenvolvimento social e económico das comunidades locais, bem como para a regeneração e revitalização de áreas urbanas deprimidas ou decadentes (Evans \& Shaw, 2006; Gunay \& Dokmeci, 2012; McKenzie \& Hutton, 2015).

Este artigo não tem qualquer pretensão de levar a cabo uma discussão teórica aprofundada sobre dois conceitos - cultura e artes - que encerram em si uma complexidade que vai muito para além dos seus objectivos, posicionando-se num terreno epistemológico complexo, relacional e de fronteiras indefinidas, em que os mundos urbanos se articulam com as dinâmicas culturais e artísticas, gerando dinâmicas de transformação e mudança (Miles, 2007). Como sugere Álvaro Domingues (2018), a cultura remete para práticas, predisposições ou imaginários diversos, articulados por protagonistas plurais e heterogéneos, cujo denominador comum é a capacidade de se misturarem e enraizarem em contextos localizados. O exercício que se pretende levar a cabo é justamente o de tentar desvendar o modo como, num contexto histórico-geográfico particular - o Barreiro contemporâneo - alguns destes elementos culturais e artísticos se articulam com as actuais dinâmicas de regeneração urbana e dialogam com a memória e a identidade deste território.

O principal objectivo deste artigo é, numa lógica de complementaridade relativamente a outros trabalhos que têm vindo a ser desenvolvidos sobre a cultura e as artes no Barreiro contemporâneo (Costa \& Lopes, 2018; Costa et al., 2019) e noutros contextos similares (Marques, 2015), colocar em evidência o modo como este processo de transformação urbana é apreendido e interpretado. Não iremos, porém, abordar aspectos relacionados com o processo de evolução histórico-geográfica do Barreiro, existindo já uma vasta produção de natureza científica e técnica sobre esta matéria (Almeida, 1988; Faria, 2010), na qual estão plasmados os principais traços definidores deste território, designadamente a sua condição pós-industrial.

\section{Metodologia}

Neste estudo, privilegia-se uma abordagem hermenêutico-interpretativa focada nas subjectividades, discursos e representações. Foram realizadas 15 entrevistas semiestruturadas a actores-chave detentores de um conhecimento privilegiado sobre as dinâmicas de transformação do Barreiro, devido aos seus percursos socioprofissionais, políticos e cívicos, bem como aos papéis que têm desempenhado nos domínios cultural e artístico. Além deste critério essencial, que possibilita uma leitura diacrónica do processo aqui investigado, procurou-se também que o conjunto dos entrevistados apresentasse um perfil diversificado em termos de género (seis mulheres e nove homens), idade (dos 31 aos 67 anos) e actividade socioprofissional (maioritariamente dirigentes associativos, artistas, autarcas e técnicos superiores).

As entrevistas foram realizadas entre Março de 2018 e Maio de 2019 e, com autorização dos entrevistados, cujo anonimato foi preservado, gravadas e posteriormente transcritas para análise. O guião da entrevista encontrava-se estruturado em torno de seis dimensões analíticas, com objectivos complementares: i) enquadramento - focada no percurso e na leitura do entrevistado sobre o papel da cultura e das artes no desenvolvimento do Barreiro; ii) espaços culturais e artísticos - centrada na identificação e descrição dos locais/eventos culturais e artísticos mais relevantes; iii) rede sócio-institucional - orientada para perceber o modo como os diferentes actores do panorama cultural e artístico barreirense se articulam entre si; iv) imagem/identidade - centrada nas características e elementos históricos e territoriais definidores do Barreiro; v) desenvolvimento cultural e artístico - assente na elaboração de uma matriz SWOT sobre a situação actual; vi) perspectivas para o futuro - focada na antecipação do futuro do Barreiro, em particular nos domínios cultural e artístico.

\section{Memória e identidade em territórios pós-industriais}

Os territórios pós-industriais, pela espessura do seu passado, encerram em si um conjunto de significados profundamente enraizados e inextricavelmente ligados à sua memória e identidade, sendo esta entendida enquanto conjunto de características socioculturais que imprimem carácter aos territórios (Crang, 2000). Quando esses significados são, de algum modo, traumáticos, pode até falar-se de "cicatrizes pós-industriais" (Storm, 2014). Num contexto como o do mundo ocidental desenvolvido, marcado por profundas transformações do seu aparelho produtivo, designadamente pela sua paulatina desindustrialização, e acompanhado de um recurso cada 
vez mais frequente às estratégias de regeneração urbana através da cultura e das artes, a memória e a identidade são recursos absolutamente vitais que, por um lado, funcionam enquanto tecido conjuntivo deste tipo de processos e, por outro, alavancam o seu próprio desenvolvimento.

Como sugere Gospodini (2006), as paisagens emergentes da cidade pós-industrial são estruturadas em torno de novos epicentros, alguns deles de natureza cultural e artística. Memória e identidade emergem, neste quadro, enquanto recursos eminentemente endógenos que são mobilizados e alimentam este tipo de processos de transformação urbana. Efectivamente, é muitas vezes em torno de vestígios do passado - real ou mitificado - que se edificam e projectam as visões para o futuro das cidades. Quer se trate de monumentos, ruínas fabris, infra-estruturas abandonadas ou lendas e narrativas socialmente construídas em torno de eventos históricos, é a partir destes fragmentos ou artefactos do passado que as comunidades criam e partilham memórias, forjando assim a sua matriz identitária, embora este não seja um processo linear (DeSilvey \& Edensor, 2013; Orange, 2015).

O trabalho de Borrup (2016), por exemplo, ao incidir sobre o papel da cultura e das artes na revitalização comunitária, coloca em evidência alguns dos desafios associados à necessidade de constantemente se renegociar a memória e a identidade dos territórios. Uma das principais lacunas deste tipo de processos decorre precisamente da exclusão, ou silenciamento, das experiências e das histórias tal qual elas são vividas quotidianamente. Tudo aquilo que serve para forjar o espírito de pertença aos lugares deve ser tido em conta. Só assim os processos de regeneração urbana através da cultura e das artes poderão ser apropriados de modo significativo (Lin \& Hsing, 2009; Prior \& Blessi, 2012).

Por outras palavras, é necessário enraizar os processos nos lugares, tornando-os consistentes com o património histórico local, a sua memória e identidade. Como sublinham Sacco e Blessi (2009, p. 1131), "o poder desenvolvimentista da cultura não pode libertar-se se o impulso top-down inicial não for equilibrado com uma significativa dinâmica de participação social bottom-up". Caso contrário, as clivagens e tensões acumuladas entre burocratas, operando enquanto forças dominantes, e actores oriundos da sociedade civil, que se sentem, em larga medida, instrumentalizados e manipulados, dão origem a conflitos que, se não forem devidamente geridos, podem criar divergências inultrapassáveis e redundar no fracasso deste tipo de processos.

Um outro elemento importante a considerar, quando se discute a problemática das relações entre território, memória e identidade, designadamente em contextos pós-industriais, prende-se com o lugar que neles ocupa o património industrial. De acordo com Lusiani e Panozzo (2016), a reflexão em torno desta questão encontra-se normalmente associada a dois discursos. Por um lado, o discurso da preservação, cujo objectivo principal é estabelecer e legitimar antigas áreas, instalações ou complexos industriais como parte do património cultural que merece ser preservado e se encontra associado à musealização. Este é um processo que não é inteiramente desprovido de polémicas, designadamente quando, por vezes, se preservam fragmentos do passado, através da sua monumentalização, sem atender à necessidade de o fazer de forma integrada no tecido histórico e urbano, respeitando o legado social, cultural e político dos lugares. Quando isso ocorre, diz-nos Balibrea (2003, p. 38), "estes fragmentos não se limitam a perder toda a função prática (...) a sua recontextualização espacial, a nova sintaxe do espaço, tende a desconectá-los da história local onde tinham sentido (...) ficam no espaço como citações planas e mudas". Por outro lado, existe também um discurso de pendor mais estratégico, que se tem vindo a impor cada vez mais como dominante, que coloca o foco no valor potencial associado à reutilização de antigas áreas industriais, designadamente por via do desenvolvimento de processos de regeneração através da cultura e das artes.

A este respeito, Lysgard (2016), por exemplo, sugere a existência de três grandes estratégias. A primeira coloca a tónica nos processos socioculturais, com enfoque na dinamização e na revitalização da vida urbana, na promoção de uma cultura cívica vibrante e interveniente, bem como no reforço da coesão social e da identidade territorial dos espaços em que se desenrola. Deste ponto de vista, são decisivos o envolvimento e a participação dos cidadãos, bem como a existência de uma densidade patrimonial que traduz e consolida a própria memória e identidade dos lugares. A segunda estratégia visa fundamentalmente tornar os territórios intervencionados mais apetecíveis e atractivos, desempenhando as actividades turística e empresarial papéis particularmente relevantes neste processo. A promoção de múltiplas formas de consumo requer a existência de uma miríade de actividades e iniciativas que sejam capazes de configurar a cidade enquanto organismo vibrante e pulsátil. A existência de festivais, de marcos arquitectónicos e monumentos culturais, de múltiplas expressões artísticas, entre outros elementos susceptíveis de mobilizar instrumentalmente algumas das facetas identitárias mais relevantes, são vitais para que esta estratégia se possa materializar (Richards \& Palmer, 2010). Por último, uma terceira estratégia, que apresenta um pendor mais nitidamente mercantil e economicista, baseando-se na criação daquilo que, num sentido lato, pode designar-se por economia cultural e artística, ou seja, na articulação 
virtuosa da cultura e das artes com o tecido social e económico dos territórios, estimulando a criação de emprego e o crescimento económico. O paradigma da "cidade criativa" (Mould, 2015), cuja influência é indiscutível, encontrar-se-á, seguramente, entre estas duas últimas estratégias, oscilando entre uma e outra, dependendo das perspectivas territoriais e das concomitantes opções políticas que as autoridades locais adoptem e decidam promover, respectivamente.

Apesar de o discurso estratégico ser hoje predominante, verifica-se que este pode adquirir diferentes configurações, dependendo do tipo de dinâmicas, sectores e actividades que são considerados prioritários. O desafio de combinar justiça social e competitividade económica, uma espécie de quadratura do círculo, tem-se revelado um dos aspectos mais problemáticos das estratégias de regeneração urbana através da cultura e das artes. Procurando dar resposta a este desafio, Sacco et al. (2014) defendem a necessidade de adoptar um "novo pensamento territorial", necessariamente sofisticado, multicausal e dinâmico, capaz de articular virtuosamente as diferentes peças do complexo puzzle do desenvolvimento baseado na cultura e nas artes. O valor acrescentado que estas comportam não pode reduzir-se única e exclusivamente nem à sua expressão económica, nem à sua capacidade de se constituir enquanto tecido conjuntivo susceptível de, alicerçado na memória e no património histórico, reconstruir as identidades locais, nem a quaisquer outras consequências habitualmente associadas à cultura e às artes.

\section{Horizontes da memória: (re)construindo a identidade do Barreiro}

Ao longo do século XIX, um pouco por todo o país, assistiu-se à progressiva multiplicação de sociedades filarmónicas e colectividades, verdadeiras arenas de expressão cultural e artística e de construção de memória colectiva. Deste modo, criou-se uma imbricada rede de espaços de sociabilidade que, como sugere Pereira (2013), funcionavam enquanto locais de reunião, lazer, elevação cultural e emancipação social, inserindo-se nas comunidades e relacionando-se com elas. O Barreiro, diz-nos MR $^{2}$ (homem, 65 anos, jornalista),

nasceu essencialmente com a cultura ferroviária e depois a indústria corticeira, que cria uma cultura muito operária, que tem a ver com a época, com as ideias socialistas, as ideias ligadas ao Antero de Quental, às Conferências do Casino. (...) E essas pessoas têm (...) a fábrica, mas depois querem alimento espiritual... então, isso dá origem ao nascimento das filarmónicas, dá origem ao movimento asso- ciativo, à cultura do Esperanto, o movimento anarquista, por aí fora. O Barreiro sempre foi uma terra que procurou ter uma visibilidade, uma intervenção cultural, através da música, do teatro. E isso propaga-se do século XIX para o século xx com alguma dinâmica.

Com efeito, as colectividades eram também espaços de resistência e contestação "ligados ao movimento reivindicativo dos trabalhadores (...) fortemente marcados pela experiência e resistência à imposição de uma nova organização do trabalho" (Pereira, 2013, p. 248), sendo nesse contexto que o Barreiro é visto como um "espaço de tradição revolucionária" (Pereira, 1993, p. 75). Como sugere RM (homem, 50 anos, técnico superior),

a cultura e a identidade que o Barreiro tem é baseada em três coisas, acho eu: primeiro, a migração das pessoas do Alentejo, que é a estrutura-base; a densidade social que ocorre dessa proximidade relacional que vem do campo e do Alentejo... um dos traços principais do território é a solidariedade. (...) O segundo traço identitário é a CUF³, que permitiu e acolheu esta migração de pessoas, mas que depois criou uma cultura própria do Barreiro. Uma cultura que tem o antes e o depois do 25 de Abril. Uma cultura de crescimento e desenvolvimento antes do 25 de Abril, e uma cultura de reacção pós25 de Abril. Depois, tens um terceiro factor fundamental, que começa em 1940 e poucos, que é a reacção comunista à CUF e o pós-CUF de cultura comunista.

O papel da CUF na transformação do Barreiro foi muito para além da sua lógica meramente económica e produtiva, tendo desempenhado um importante papel ao nível da disponibilização de equipamentos colectivos e da prestação de serviços. Fê-lo, em linha com as práticas mais habituais do grande capital industrial, no âmbito de uma estratégia "paternalista" que visava, ao mesmo tempo, o reforço da vinculação dos operários à fábrica e uma relativa pacificação social. Não é por acaso, afirma MR (homem, 65 anos, jornalista), que

a própria CUF, quando se implanta aqui, cria logo um centro para formar para a música, para as escolas, e para o desporto, criando ela própria uma dinâmica de actividades culturais. A CUF cria um dos maiores concursos de fotografia mundiais, tem os Jogos Florais, com uma importância enorme (...), os Jogos Juvenis do Barreiro, grupos de teatro, bandas de música... o Barreiro sempre foi muito inovador. 
Por conseguinte, até ao 25 de abril, a CUF tem uma capacidade aglutinadora quasi-monopolista, no que ao desenvolvimento das actividades culturais e artísticas diz respeito. Depois, tudo mudou muito rapidamente e a paisagem cultural do Barreiro reconfigurou-se, a partir de um inaudito dinamismo cívico, cultural e político que, até então, havia permanecido reprimido sob o peso da ditadura. Como salienta PV (homem, 42 anos, técnico superior),

o 25 de Abril é claramente um momento de ruptura com o passado, porque tentava fazer-se alguma coisa antes, mas havia muitas limitações. E entre 74 e 79 há uma explosão, quase um big bang de actividades culturais, movimentos associativos, entidades ligadas às artes, cultura, desporto, lazer, que explodem praticamente em todas as ruas. (...) Esse é o momento, de longe, mais marcante no Barreiro ao nível da produção e do consumo cultural. Havia relações com países de Leste que trouxeram cá e permitiram que os munícipes assistissem a espectáculos muito, muito interessantes. (...) Havia uma proximidade política com o MPLA, lembro-me de vários grupos de teatro e espectáculos de Angola, de países de Leste, uma ligação política muito forte, que permitiu assistir a eventos que, de outra forma, teria sido impossível, porque eram de grande qualidade. (...) A explosão foi de tal forma grande, que passa-se de um zero para o cem e durante ali alguns anos as pessoas estavam reprimidas, notava-se, sobretudo aquelas que dinamizavam estas actividades. Foi um período de 5 ou 6 anos de um nível muito elevado ao nível da produção.

Particularmente na primeira década após a revolução, em paralelo e fortalecendo a rede de colectividades existente, desenvolve-se também um número significativo de agentes de matriz eminentemente cultural, nomeadamente nos domínios do teatro e da música. Muitas vezes em estreita articulação com o município, organizações como a Escola de Jazz do Barreiro e o grupo de teatro ArteViva desenvolvem um leque alargado e diverso de actividades. $O$ entrecruzar do dinamismo das redes de sociabilidade de base associativa, da influência pela CUF e da liderança comunista no município contribuiu também para cultivar a ideia do Barreiro-ilha (Belanciano, 2010) e o sentimento de autossuficiência local, nomeadamente em termos culturais e artísticos, acentuados pela própria geografia e pela dificuldade de acesso à capital. Num certo sentido, a ideia de que nas margens e periferias existe o potencial para a criação de novas centralidades encontra no Barreiro um território de concretização. Como sugere AS (homem, 47 anos, gestor),
Esta relação que existe, não sei se de amor/ ódio, mas de proximidade e distância em relação a Lisboa... [O Barreiro] está relativamente próximo de Lisboa, mas acaba por estar um pouco distante, porque as acessibilidades não são as melhores. E daí ser criado quase o conceito de ilha, onde as pessoas que aqui moram têm de fazer por si, e tentar criar uma dinâmica interna própria.

A transição pós-industrial no Barreiro significou, a par do declínio económico e da degradação do edificado, um enfraquecimento do vigor sociocultural que, até aí, havia marcado o território. Com efeito, se nos anos 90 o Barreiro foi ainda palco de uma movida cultural e nocturna relevante no contexto da Margem Sul, a viragem do século sinalizou efectivamente este declínio, concretizado no encerramento de múltiplos espaços de convívio e produção, fruição, e divulgação artística e cultural - o El Matador, a Vinícola, a Chapelaria, etc. (Oliveira, 2019). Neste período, e em particular associadas ao "Barreiro Velho", cimentam-se sensações e imagens de pendor negativo sobre o território, que espelham a progressiva decadência urbana que gravita em torno do abandono e da degradação do edificado e do tecido socioeconómico, acompanhados de uma crescente sensação de insegurança (CMB, 2008), que se somam às preexistentes imagens estigmatizadas de poluição e suburbanidade. Como afirma AC (homem, 37 anos, programador cultural),

acho que no virar do milénio isto decaiu mesmo. Muito. Em termos sociais, culturais, artísticos, mas muito a ver com o tecido económico. (...) No final dos anos 2000 os miúdos da nova geração já não olhavam para o Barreiro. O Barreiro, para eles, já não era de todo esse sítio auto-sustentável, nem essa insularidade rica. Começaram naturalmente a olhar para Lisboa, porque deixou de haver coisas aqui que correspondessem ao que queriam ver ou fazer ou assistir. $E$ acho que passámos por um período de 10 ou 15 anos de esvaziamento brutal. (...) Acabámos por nos tornar naquilo que dizemos que não somos, que é um subúrbio como os outros, ou um dormitório. Acho que o Barreiro perdeu essa insularidade positiva que tinha, e ficou com a parte negativa da insularidade.

Cidade, cultura e artes: um olhar sobre o Barreiro contemporâneo

Este contexto de declínio constituiu solo fértil para o aparecimento e para a progressiva afirmação/consolidação de alguns agentes culturais particularmente activos na esfera da produção e 
programação musical. Associações culturais como a OUT.RA, a Hey, Pachuco!, e a ADAO - Associação Desenvolvimento de Artes e Ofícios - formalizam-se nos últimos 15 anos, enquanto novos colectivos locais, enraizados no território e empenhados na sua dinamização. O seu objectivo, afirma AC (homem, 37 anos, programador cultural),

é cada vez mais transformar o quotidiano. (...) Até para voltar a dar essa cor que nós conhecemos na cidade, de quando éramos putos, e que nos inspirou. (...) Há aquela relação de amor quase inexplicado por esta cidade. Só mesmo quem é daqui é que entende isto.

Os protagonistas destes colectivos, em grande parte naturais e residentes no Barreiro com ligações à cultura e às artes, apresentam traços identitários e discursos que bebem directamente do legado histórico, da memória colectiva e das suas próprias vivências num território, afirmando-se, simultaneamente, como guardiões da identidade e da memória locais e como atores que reclamam um papel activo no processo de reconfiguração do território. Os traços do distanciamento destes novos colectivos em relação às colectividades e aos agentes culturais tradicionais verificam-se em múltiplos planos: nas motivações, nas formas de organização interna, nos tipos de relações que estabelecem entre si e com o poder local, na visão que têm do e para o território, nos papéis que se propõem desempenhar no seu desenvolvimento, nos tipos de actividades que organizam e promovem e, consequentemente, nas formas de ocupação do espaço e na escala de visibilidade externa que ambicionam e que, efectivamente, alcançam.

Quando anteriormente tinhas algo [de oferta cultural] ou era oferecido pela Câmara Municipal do Barreiro (...), ou então estava a cargo das colectividades. (...) Nós inicialmente estávamos metidos nesse saco e tivemos de lutar um pouco. Uma coisa - que tem todo o valor - é a colectividade, que existe há não sei quanto tempo. Estes grupos são bastante diferentes na maneira como fazem as coisas. Pretendem profissionalizar-se em torno da arte e cultura, querem ser estruturas profissionais de programação. [TP (homem, 40 anos, músico)]

A territorialização das práticas é particularmente marcada pela utilização de múltiplos espaços, de forma permanente e itinerante, e de elementos simbólicos ligados à memória industrial, ferroviária e associativa. A actual dinâmica cultural e artística encontra (unanimemente) o seu epicentro na ADAO, instalada desde 2015 no antigo quartel da
Associação Humanitária dos Bombeiros Voluntários dos Caminhos de Ferro Sul e Sueste.

A ADAO é a coisa mais Barreiro que existe, neste momento, e uma das melhores coisas que aconteceu ao Barreiro. Porque junta um carácter associativo, que, apesar de ser dos tempos modernos, ainda tem algumas coisas do associativismo clássico, no sentido em que aquilo é um grupo mesmo grande de pessoas que, entendam-se bem ou não, é muito cooperativista. Depois porque está naquele edifício: aquilo é um paradigma do que tem de acontecer no Barreiro, e que nós desde que temos idade para pensar que achamos que devia acontecer nesta cidade, que é ocupar os espaços. Há tantos brutais. E aquilo aconteceu. Portanto é o paradigma total do que devia ser o takeover da cultura ao Barreiro. [AC (homem, 37 anos, programador cultural)]

Este equipamento de cariz ferroviário, previamente abandonado e degradado, tem-se transformado progressivamente num espaço de produção, divulgação e fruição artísticas de referência. Arrendado à CP - Comboios de Portugal, este amplo complexo é constituído por múltiplos salões, armazéns e oficinas onde coexistem, actualmente, salas de espectáculos, oficinas de produção artesanal e musical e múltiplos gabinetes cedidos a indivíduos e a colectivos, muitos deles ligados ao domínio das artes visuais e performativas e ao artesanato. É neste lugar, e particularmente nos eventos Open Day, que organiza regularmente, que as características do meio criativo local se tornam mais evidentes, constituindo um microssistema de produção e consumo (Costa \& Lopes, 2018, p. 192), assente em relações colaborativas e horizontais, e combinando uma evidente ancoragem local com um impulso aparente para maior projecção a outras escalas.

De forma distinta, na medida em que assume uma lógica reticular e difusa, a espacialização das actividades promovidas pela associação cultural OUT.RA é também reveladora da intrínseca relação com a memória e a identidade do Barreiro. Num certo sentido, esta associação cultural, ao explorar o legado industrial do Barreiro tal como o faz, promove uma reinvenção mais abrangente e novas apropriações dos lugares. Os desafios enfrentados para pôr de pé esta estratégia ficam bem patentes na descrição oferecida por AC (homem, 37 anos, programador cultural):

Começámos a bater à porta de colectividades antigas, começámos a explorar as fábricas, o espaço industrial que estava mais ou menos vedado e que, para nós, era uma coisa mais do imaginário do que uma coisa concreta. É uma 
coisa relativamente recente poderes andar por aquela zona. Portanto, no fundo, começar a coser esse amor/ódio pelo Barreiro. Ou esse amor pelo belo e pelo feio, em simultâneo. (...) Para as pessoas da cidade, ajuda a conhecer um bocado aquela experiência que tínhamos de andar à procura de sítios ou de ficar fascinados com sítios. Quando há um concerto, as pessoas vão lá e dizem: "Ah, isto existe? Nem sabia que isto estava aqui". No ano passado fizemos um concerto no Depósito da Água (...) e é assim uma coisa "Uau! Estamos a fazer concertos aqui!". As pessoas nunca tinham entrado lá dentro. E isto é supergratificante. E é simbólico. O simbolismo é importante, é relevante. (...) São movimentos de abertura que são importantes. E hoje, se calhar, os sítios já estão mais conhecidos e identificados, mas houve este processo que foi relevante.

A identificação dos locais onde decorreram as primeiras 15 edições do OUT.FEST ${ }^{4}$ (figura 1) - Festival Internacional de Música Exploratória, organizado anualmente, desde 2004, pela OUT. RA - ilustra bem a lógica de rede subjacente à apropriação dos espaços, muitos deles associados à memória industrial e ferroviária e às colectividades tradicionais, sugerindo uma certa intencionalidade no que toca à sua redescoberta e (re)introdução na dinâmica da cidade (Costa \& Lopes, 2018, p. 189).

Por outro lado, a Câmara Municipal do Barreiro (CMB) assegura, em colaboração com as colectividades e os agentes culturais tradicionais, uma programação cultural contínua, nos espectros de fruição e formação, que marcam o quotidiano local, constituindo um traço de continuidade identitária e um factor relevante, histórico e actual, de coesão socioterritorial. Contudo, os elementos com maior visibilidade são os eventos concebidos e promovidos pelos novos agentes culturais, que, honrando o legado barreirense, têm contribuído de forma determinante para a reinvenção, mais simbólica do que física, dos lugares. Exemplos particularmente ilustrativos desta tendência são, a par dos Open Day da ADAO, os festivais Barreiro Rocks e OUT.FEST.

Do alargado leque de expressões artísticas que constituem a actual "cena cultural" do Barreiro, importa ainda referir a arte urbana, cujo desenvolvimento é mais recente, pela sua capacidade de dialogar "de forma dinâmica e hábil com a cidade, com o seu edificado e ambiente material" (Campos, 2018), sendo actualmente uma das expressões artísticas mais habituais em estratégias municipais de regeneração e marketing territorial. No caso particular do Barreiro, a arte urbana apresenta um conjunto de traços distintivos, quer ao nível dos processos, quer ao nível dos resultados. Uma parte substancial das obras de arte urbana que nos últimos anos têm transfigurado a paisagem urbana e o espaço público do Barreiro são produtos de artistas locais directa ou indirectamente ligados ao Núcleo de Arte Urbana da ADAO, que promove, em parceria com a Câmara Municipal do Barreiro, as iniciativas Art in Town e Dia B. Apesar de efémera, a arte urbana acaba por ser uma das expressões artísticas mais presentes no quotidiano

Figura $1 \triangleright$ Locais utilizados para actuações artísticas no âmbito do OUT.FEST (2004-2018)

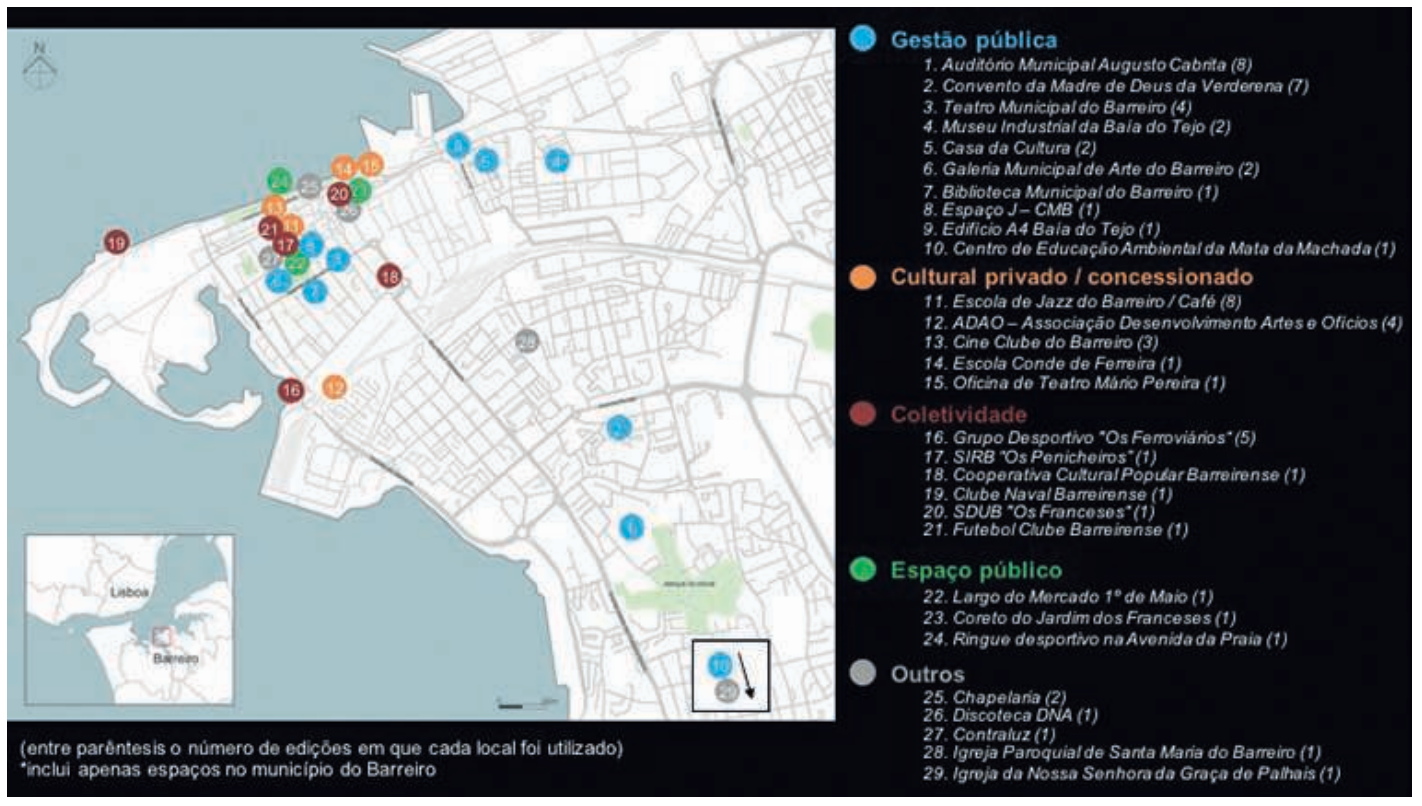

Fonte: Elaboração própria. 
da cidade, particularmente ao nível das temáticas e das simbologias, verificando-se um apelo constante (induzido e pró-activo) à recuperação da memória e da identidade local. As primeiras edições do Art in Town (2016 e 2017), aliás, instituíram como tema a "Memória Barreirense", resultando em múltiplas representações artísticas de personalidades locais, e de episódios e elementos históricos relevantes para o desenvolvimento do Barreiro. mediático, mas carácter efémero; iii) a instauração paulatina de um certo populismo demagógico, sem critérios explícitos e públicos de qualidade. Efectivamente, sendo um elemento nuclear da promoção cultural e artística, a CMB parece carecer de uma estratégia integrada para o sector, afirmando-se, predominantemente, como entidade intermediária e facilitadora de diálogo entre outros protagonistas (locais e externos).

Figura $2 \triangleright$ Representação de memória e identidade local na arte urbana do Barreiro

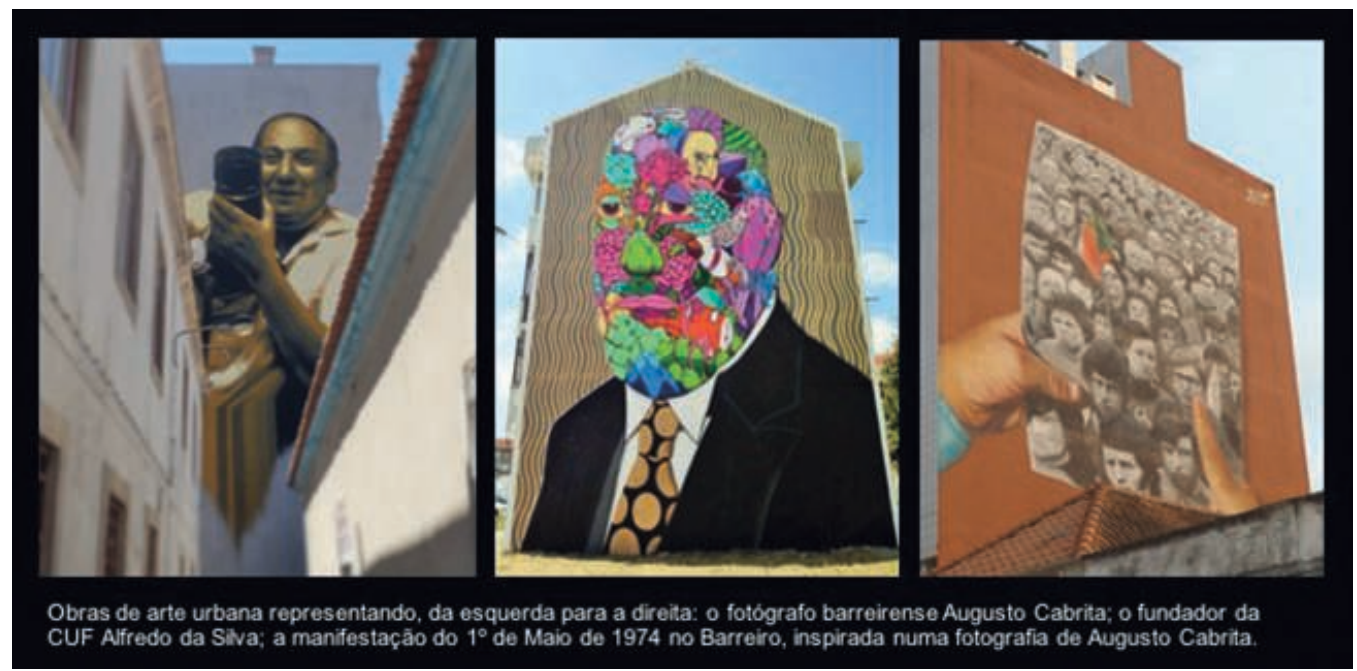

Fonte: Elaboração própria, créditos fotográficos de Ana Pinto (Outra História. Turismo | Património).

\section{Considerações finais}

No Barreiro, a memória e a identidade são, hoje, porventura mais do que nunca, recursos endógenos que os diferentes protagonistas do actual processo de regeneração urbana, sobretudo os novos agentes culturais e a CMB, têm mobilizado, ainda que de formas distintas, para dar forma à sua intervenção no domínio da cultura e das artes. Tal como no estudo conduzido por Clavier e Kauppinen (2014), também no Barreiro é possível verificar a existência de uma rede - estruturada em torno da cultura e das artes - em que actores públicos e privados, formais e informais, operando a diferentes níveis políticos, se envolvem e contribuem para a dinamização cultural e artística deste território. Esta rede, porém, não traduz a existência de uma política cultural urbana explícita cuja força motriz é a autarquia local. Pelo contrário, a partir da leitura da proposta de Lopes (2009), aquilo que efectivamente parece existir, são alguns indícios da sua ausência, tais como: i) a presença de um conjunto desarticulado de iniciativas dispersas no espaço e no tempo; ii) a existência de um punhado de acções espectaculares com impacto
A análise feita sugere também que, contrariamente àquilo que poderíamos ser levados a crer, com base no grande entusiasmo que hoje parece existir em torno da dinâmica em desenvolvimento no Barreiro, a cultura e as artes fazem parte do seu património histórico e não são um fenómeno inteiramente novo. Aquilo que existe, isso sim, são novos protagonistas que têm introduzido elementos inovadores - ao nível do modo de funcionamento e da cultura organizacional, por exemplo - no modo como a cultura e as artes são mobilizadas, no âmbito de processos de transformação territorial.

Por outro lado, até ao momento, parecem não existir tensões ou conflitos significativos entre os diferentes intervenientes. Embora seja uma afirmação que carece de maior fundamentação empírica, arriscamos dizer que, porventura, essa ausência se deve, pelo menos em parte, à força da memória e da identidade que, pela sua grande capacidade de inscrição material e simbólica no território, operam enquanto tecido conjuntivo, promovendo coesão socioterritorial.

Embora existam alguns exemplos que podemos associar à lógica da preservação, parece existir um 
certo predomínio do discurso de tipo estratégico. Este, por sua vez, parece apontar para a coexistência de diferentes modalidades, embora as facetas históricas, cívicas e políticas da cultura e das artes no Barreiro pareçam desempenhar um papel mais significativo ao nível das representações e ideários dos actores-chave entrevistados e, assim, sugerir a existência de limitações ou condicionalismos que podem, eventualmente, obstaculizar a afirmação de dinâmicas culturais e artísticas de natureza eminentemente mercantil e/ou empresarial.

As expressões locais de solidariedade e sociabilidade reflectem-se, ainda hoje, numa sólida rede de relações de proximidade e num expressivo número de colectividades e agentes culturais que, em articulação com a CMB, marcam o ritmo da vivência quotidiana do concelho e constituem elementos fundamentais na coesão socioterritorial. Até ao momento, por exemplo, não parece ainda existir aquilo que anteriormente designámos por economia cultural e artística, e as tentativas de desenvolvimento do Barreiro enquanto "cidade criativa" não têm tido grande sucesso. No entanto, a actual promoção do Parque Empresarial do Barreiro enquanto espaço incubador de indústrias criativas, através da atracção de agentes externos, numa procura de articulação virtuosa da cultura e das artes com criação de emprego e crescimento económico, contribuindo assim para a afirmação de dinâmicas de mercadorização e neutralização cultural e artística (Guinard \& Margier, 2018), sugere que existe margem para que esta estratégia ganhe força.

Por último, os novos agentes culturais afirmam-se, simultaneamente, como agentes de preservação da identidade e memória locais e como actores que reclamam um papel activo no processo de redefinição identitária do território, designadamente através da promoção de uma maior abertura ao exterior e vontade de captação de públicos externos. Continuidade e redefinição identitária reflectem-se, por exemplo, na reutilização dos lugares associados à memória local e nas simbologias das expressões artísticas e culturais que promovem, sendo muitos deles parte integrante do património barreirense. Ainda que, pela sua natureza fragmentária e vestigial, estes lugares se encontrem sujeitos às dinâmicas de recontextualização espacial que anteriormente descrevemos, ao estabelecerem um elo de ligação entre o passado e o presente, promovem a criação de novas paisagens urbanas que revisitam a matriz identitária barreirense.

\section{Notas}

1 Esta investigação foi desenvolvida no âmbito do projecto Ágora - Encontros entre a cidade e as artes: explorando novas urbanidades [PTDC/ATP-GEO/3208/2014], apoiado pela Fundação para a Ciência e a Tecnologia.
2 Para preservar o anonimato dos entrevistados, foram usadas iniciais fictícias, identificando-se ainda o género, a idade e a actividade socioprofissional.

3 Companhia União Fabril.

4 Reconhecido, em 2017-2018, com o título de "Remarkable Festival" pela EFFE - Europe for Festivals Festivals for Europe.

\section{Referências bibliográficas}

Almeida, A. N. (1988). Perfis demográficos e modos de industrialização - o caso do Barreiro. Análise Social, XXIV(100), 449-460.

Balibrea, M. P. (2003). Memória e espaço público na Barcelona pós-industrial. Revista Crítica de Ciências Sociais, 67, 31-54.

Belanciano, V. (2010, 24 de novembro) Barreiro, uma ilha à espera de ser redescoberta. Jornal Público. Disponível em https://www.publico.pt/2010/11/24/ culturaipsilon/noticia/barreiro-uma-ilha-a-espera-de-ser-redescoberta-270173

Borrup, T. (2016). Creative Placemaking: Arts and Culture as a Partner in Community Revitalization. In Fundamentals of Arts Management, University of Massachusetts.

Campbell, P., Cox, T. \& O'Brien, D. (2017). The social life of measurement: how methods have shaped the idea of culture in urban regeneration. Journal of Cultural Economy, 10(1), 49-62.

Campos, R. (2018). O contexto da arte urbana emergente. Seara Nova, 1741(Inverno 2017/18), disponível em http://www.searanova.publ.pt/ pt/1741/cultura/762/

Clavier, B., \& Kauppinen, A. (2014). Art for integration: political rationalities and technologies of governmentalisation in the city of Malmö. Identities, 21(1), 10-25.

CMB (2008). Programa de reabilitação urbana para o Barreiro Antigo, Barreiro, Portugal.

Costa, P., \& Lopes, R. (2018). Creative milieus in the metropolis' periphery: from the massification of Lisbon's city centre to the liveliness of "Margem Sul". In L. Lazzeretti \& M. Vecco (Eds.), Creative Industries and Entrepreneurship: Paradigms in Transition from a Global Perspective (177-198). Reino Unido: Edward Elgar Publishing.

Costa, P., Lopes, R. V., \& Bassani, J. (Eds.) (2019). BRR 2018: Quando a periferia se torna trendy. Lisboa: DINÂMIA'CET-IUL - Centro de Estudos sobre a mudança Socioeconómica e o Território, Instituto Universitário de Lisboa (Portugal). São Paulo: Faculdade de Arquitetura e Urbanismo, Universidade de São Paulo (Brasil).

Crang, M. (2000). Cultural Geography. Londres: Routledge.

DeSilvey, C., \& Edensor, T. (2013). Reckoning with ruins. Progress in Human Geography, 37(4), 465-485.

Domingues, A. (2018). Braga: Espaços, culturas e contemporaneidade. Contributos para repensar a cidade e a cultura. In J. Teixeira (Org.), Espa- 
ços, Culturas Urbanas e Contemporaneidade (pp. 17-39). Vila Nova de Famalicão: Edições Húmus.

Evans, G., \& Shaw, P. (2006). Literature Review: Culture and Regeneration. Arts Research Digest, 37, 1-11.

Faria, C. V. (2010). Industrialização e Urbanização em Portugal: que relações? O caso do Anteplano de Urbanização da Vila do Barreiro de 1957. Malha Urbana, 9, 79-101.

Gospodini, A. (2006). Portraying, classifying and understanding the emerging landscapes in the post-industrial city. Cities, 23(5), 311-330.

Guinard, P., \& Margier, A. (2018). Art as a new urban norm: Between normalization of the City through art and normalization of art through the City in Montreal and Johannesburg. Cities, 77, 13-20.

Gunay, Z., \& Dokmeci, V. (2012). Culture-led regeneration of Istanbul waterfront: Golden Horn Cultural Valley Project. Cities, 29, 213-222.

Lin, C.Y., \& Hsing, W.C. (2009). Culture-led Urban Regeneration and Community Mobilisation: The Case of the Taipei Bao-an Temple Area, Taiwan. Urban Studies, 46(7), 1317-1342.

Lopes, J. T. (2009). Políticas Culturais Urbanas. In C. Fortuna \& R. P. Leite (Orgs.), Plural de Cidade: Novos Léxicos Urbanos (pp. 171-184). Coimbra: Almedina.

Lusiani, M. \& Panozzo, F. (2016). Culture on top: Beyond museification and culture-led regeneration of industrial heritage (Università Ca' Foscari Venezia Department of Management Working Paper No. 2016/ 02). Retirado do website da Università $\mathrm{Ca}^{\prime}$ Foscari Venezia: http://virgo.unive.it/wpideas/ storage/2016wp02.pdf

Lysgard, H. K. (2016). The "actually existing" cultural policy and culture-led strategies of rural places and small towns. Journal of Rural Studies, 44, 1-11.

Marques, C. A. (2015). Planeamento Cultural Urbano em Áreas Metropolitanas: Revitalização dos espaços pós-suburbanos. Casal de Cambra: Caleidoscópio.

McKenzie, M., \& Hutton, T. (2015). Culture-led Regeneration in the Post-industrial Built Environment: Complements and Contradictions in Victory Square, Vancouver. Journal of Urban Design, 20(1), 8-27.

Miles, M. (2007). Cities and Urban Cultures. Abingdon: Routledge.
Mould, O. (2015). Urban Subversion and the Creative City. Abingdon: Routledge.

Oliveira, A. (2019). Cenas musicais barreirenses. Entre a independência e a colaboração. In P. Costa, R. V. Lopes \& J. Bassani (Eds.), BRR 2018: Quando a periferia se torna trendy. Lisboa: DINÂMIA'CET-IUL - Centro de Estudos sobre a mudança Socioeconómica e o Território, Instituto Universitário de Lisboa (Portugal). São Paulo: Faculdade de Arquitetura e Urbanismo, Universidade de São Paulo.

Orange, H. (Ed.) (2015). Reanimating Industrial Spaces: Conducting Memory Work in Post-industrial Societies. Califórnia, Estados Unidos da América: Left Coast Press.

Pereira, J. (2013). A produção social da solidariedade operária: o caso de estudo da Península de Setúbal (1890-1930) (tese de doutoramento em História Contemporânea). Lisboa: Faculdade de Ciências Sociais e Humanas, Universidade Nova de Lisboa.

Pereira, J. P. (1993). A Sombra - Estudo sobre a clandestinidade comunista. Lisboa: Gradiva.

Prior, J., \& Blessi, G. (2012). Social Capital, Local Communities and Culture-led Urban Regeneration Processes: The Sydney Olympic Park Experience. Cosmopolitan Civil Societies Journal, 4(3), 78-96.

Richards, G., \& Palmer, R. (2010). Eventful cities: Cultural management and urban revitalization. Oxford: Elsevier.

Sacco, P., \& Blessi, G. (2009). The Social Viability of Culture-led Urban Transformation Processes: Evidence from the Bicocca District, Milan. Urban Studies, 46(5\&6), 1115-1135.

Sacco, P., Ferilli, G. \& Blessi, G. (2014). Understanding culture-led local development: A critique of alternative theoretical explanations. Urban Studies, 51(13), 2806-2821.

Storm, A. (2014). Post-Industrial Landscape Scars. Nova Iorque, Estados Unidos da América: Palgrave Macmillan.

Vickery, J. (2007). The emergence of culture-led regeneration: a policy concept and its discontents (University of Warwick - Centre for Cultural Policy Studies Working Paper No. 9). Retirado do website da Universidade de Warwick: https://warwick. ac.uk/fac/arts/theatre_s/cp/research/publications/ centrepubs/ccps.paper9.pdf

Esta obra está licenciada com uma Licença Creative Commons Atribuição - 4.0 (CC BY 4.0).

Recebido a 24/05/2019. Aceite para publicação a 07/10/2019

André Carmo (acarmo@uevora.pt). Departamento de Geociências, Escola de Ciências e Tecnologia da Universidade de Évora / Centro de Estudos Geográficos, Instituto de Geografia e Ordenamento do Território da Universidade de Lisboa, Departamento de Geociências, Colégio Luís António Verney, Rua Romão Ramalho, n. ${ }^{0}$ 59, 7000-671 Évora. Filipe Matos (filipematos@campus.ul.pt). Centro de Estudos Geográficos, Instituto de Geografia e Ordenamento do Território da Universidade de Lisboa, R. Branca Edmée Marques, 1600-276 Lisboa.

Sónia Pereira (spereiramx@gmail.com). Centro de Estudos Geográficos, Instituto de Geografia e Ordenamento do Território da Universidade de Lisboa, R. Branca Edmée Marques, 1600-276 Lisboa. 